\title{
Wenn Oberflächen lebendig werden
}

Liebe Leserinnen, liebe Leser,

seit ich im Juli 2021 als Redakteurin für JOT - Journal für Oberflächentechnik arbeite, sehe ich meine Umgebung mit anderen Augen. Wenn ich in mein Auto steige, sehe ich imposante Straußenfederwalzen, die über Karosserieoberflächen streifen und diese entstauben. Ich sehe Roboter, die in anmutigen Bewegungen Lack hochfein und zielgerichtet aufsprühen. Ich sehe Anlagen, in denen heißes Wachs aus unzähligen 360-Grad-Düsen in die Hohlräume eines Unterbodens gespritzt wird.

Und diese Technologien sind Staus Quo - bei einem Blick Richtung Zukunft wird es noch spannender. Denn die Mobilitätsbranche befindet sich in einem tiefgreifenden Wandlungsprozess. Dabei kann Oberflächentechnik einiges bewegen. So kann sie zur Energieeinsparung im Betrieb des Transportmittels beitragen. Stichwort Leichtbau: über Bauteile aus leichteren Werkstoffen, die dank entsprechender Beschichtung dieselben Funktionen erfüllen. Stichwort Aerodynamik: über Lacke, die zum Beispiel eine Haifischhaut-Struktur aufweisen und so den Luftwiderstand verringern - beim Auto nicht wirklich relevant, aber für die Flugzeugindustrie durchaus ein Thema. Oder Stichwort Funktionalisierung: über eine Digitalisierung der Karosserieoberfläche mit Chamäleon-Effekt, der Heiz- und Klimatisierungsenergie einsparen kann. Wie das geht? Statt eines Lacks wird eine Folie, die im Prinzip wie das Display eines E-BookReaders funktioniert, auf die Fahrzeugoberfläche aufgebracht. Die Farbe des Autos lässt sich damit per Knopfdruck verändern. An heißen Sommertagen kann man eine helle, das Sonnenlicht reflektierende Fahrzeugfarbe wählen und im Winter eine dunkle, lichtabsorbierende. Die Karosserieoberfläche wird so praktisch lebendig. Lesen Sie mehr darüber im Beitrag ab Seite 12 .

Natürlich muss man das ganzheitlich betrachten und zum Beispiel auch die Energie berücksichtigen, die für die Erzeugung und den Betrieb der Folie benötigt wird aber grundsätzlich ist das ein tolles Zukunftsthema. Faszinierend, was alles möglich wird, wenn Menschen die Perspektive wechseln, interdisziplinär und firmenübergreifend zusammenarbeiten, innovative Technologien nutzen und sich die Natur als Vorbild nehmen. Ich bin jedenfalls gespannt, wo die Reise der Oberflächentechnik noch hingeht.

Eine interessante Lektüre wünscht Ihnen

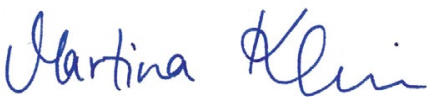

Martina Klein

Redakteurin

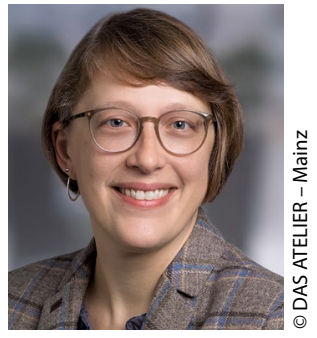

Gerne können wir uns auch auf Xing und/oder Linkedin vernetzen:

https://www.xing.com/profile/Martina Klein99/cv

https://www.linkedin.com/in/martinaklein-724625208/
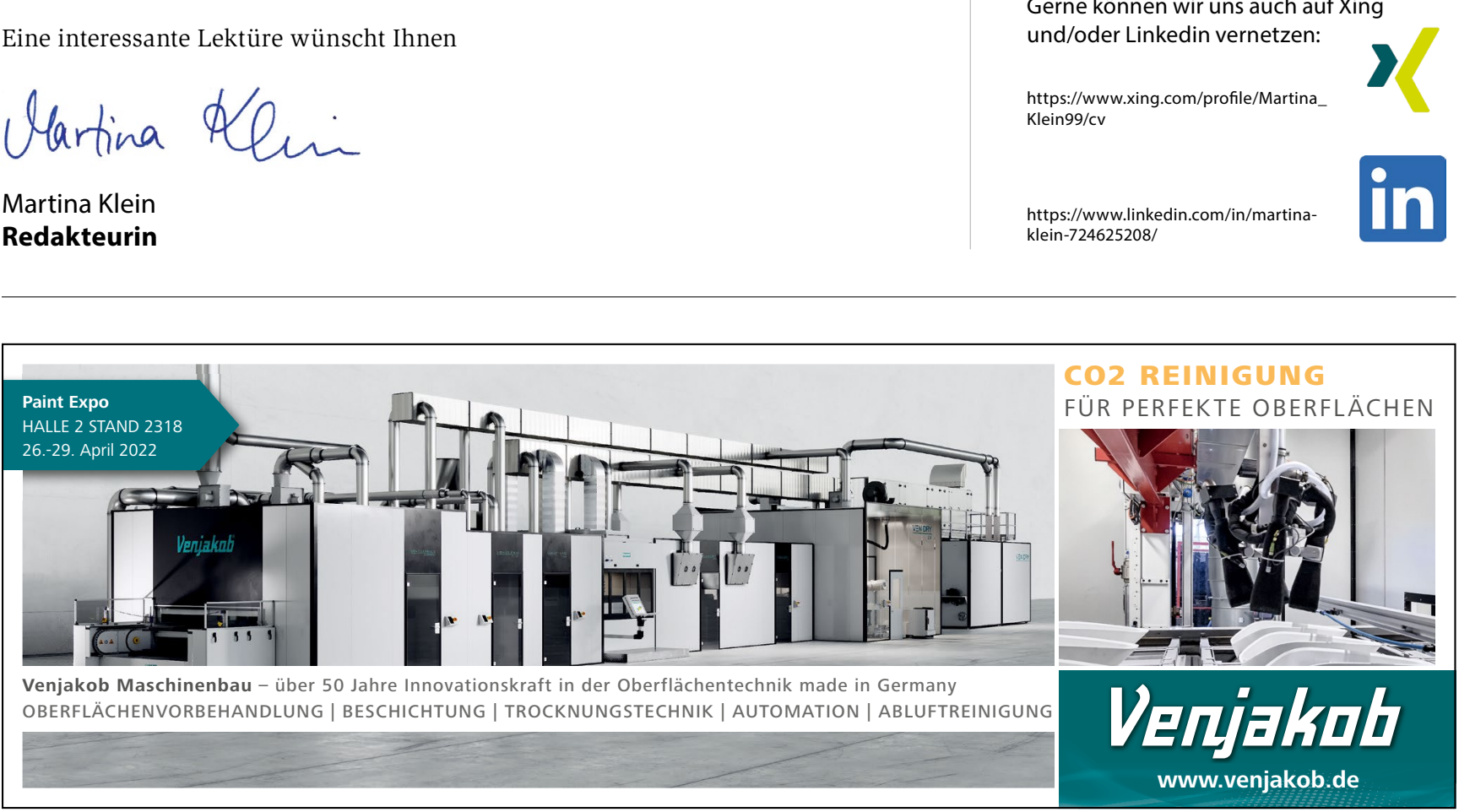